\title{
EVALUASI KERUSAKAN PERKERASAN LENTUR RUAS TOL JAKARTA- CIKAMPEK DAN ALTERNATIF PENANGANANNYA
}

\author{
Hans Hendito ${ }^{1}$ dan Anissa Noor Tajudin ${ }^{2}$ \\ ${ }^{1}$ Program Studi Sarjana Teknik Sipil, Universitas Tarumanagara, Jl. Letjen S. Parman No.1 Jakarta \\ hans.325160088@stu.untar.ac.id \\ ${ }^{2}$ Program Studi Sarjana Teknik Sipil, Universitas Tarumanagara, Jl. Letjen S. Parman No.1 Jakarta \\ anissat@ft.untar.ac.id
}

Masuk: 14-07-2021, revisi: 18-11-2021, diterima untuk diterbitkan: 18-11-2021

\begin{abstract}
The most common causes of road damage are the design life of the road that has been passed, waterlogging on the road due to poor drainage, or even traffic load which can cause the service life of the road to be shorter than planned. To find out the conditions on the Jakarta-Cikampek Toll Road. Calculates the value of road pavement conditions calculated using the Indeks Kondisi Perkerasan (IKP) on the Jakarta-Cikampek Toll Road. To find out what kind of treatment we should do for the damage that occurs. The Indeks Kondisi Perkerasan is a quantitative indicator of pavement conditions that has a range of values ranging from $0-100$, with a value of 0 representing the worst pavement condition while 100 representing the best pavement condition. The IKP method has a level of handling type for each IKP value. According to the IKP guidelines, the type of handling that must be carried out with an average IKP value of 96,32 is routine maintenance. For further research, it's necessary to conduct a direct survey, so that accurate results can be obtained. It is necessary to study with various methods to be able to compare the level of accuracy of a method.
\end{abstract}

Keywords: IKP; Pavement Condition, Distress

\begin{abstract}
ABSTRAK
Penyebab kerusakan jalan yang paling umum adalah umur rencana jalan yang telah dilewati, genangan air pada jalan yang diakibatkan drainase yang buruk, atau bahkan beban lalu lintas yang berlebihan yang dapat menyebabkan umur pakai jalan akan menjadi lebih pendek daripada perencanaannya. Untuk mengetahui kondisi pada jalan Tol JakartaCikampek. Menghitung nilai kondisi perkerasan jalan jika dihitung dengan Indeks Kondisi Perkerasan (IKP) pada ruas Tol Jakarta-Cikampek. Untuk mengetahui penanganan seperti apa yang harus kita lakukan terhadap kerusakan yang terjadi. Kondisi Perkerasan atau IKP adalah indikator kuantitatif (numerik) kondisi perkerasan yang mempunyai rentang nilai mulai $0-100$, dengan nilai 0 nya menyatakan kondisi perkerasan paling jelek sementara 100 menyatakan kondisi perkerasan terbaik. Metode IKP memiliki tingkat jenis penanganan tiap nilai IKP. Menurut pedoman IKP, jenis penanganan yang harus dilakukan dengan nilai IKP rata-rata 96,32 adalah pemeliharaan rutin. Untuk penelitian selanjutnya, perlu untuk survei secara langsung, supaya hasil yang didapat lebih maksimal. Perlu diteliti dengan metode yang beragam untuk dapat membandingkan tingkat keakuratan sebuah metode.
\end{abstract}

Kata kunci: IKP; Kondisi Perkerasan; Kerusakan

\section{PENDAHULUAN}

Perkembangan kebutuhan manusia yang terus meningkat dari waktu ke waktu menuntut tersedianya sarana dan prasarana. Sarana dan prasarana transportasi merupakan salah satu aspek yang sangat vital dalam pemenuhan kebutuhan manusia, sehingga kinerja sarana dan prasarana sangat harus dimaksimalkan. Jalan sebagai prasarana transportasi utama memiliki fungsi yang sangat penting bagi kebutuhan manusia. Untuk itu masyarakat memerlukan jalan raya yang nyaman serta aman untuk penggunanya, dan diharapkan bisa dapat meningkatkan perindustrian serta pereknomian masyarakat. Tetapi bersamaan jalannya waktu, jalan raya tentu alami penurunan kondisi sesuai dengan bertambah usia dari jalan tersebut, sehingga jalan raya tersebut hendak menjadi suatu hambatan untuk penggunanya.

Penyebab kehancuran jalan yang sangat universal yakni usia rencana jalur yang sudah dilewati, genangan air pada jalan yang disebabkan drainase yang kurang baik, ataupun beban lalu lintas yang melampaui batas (overload) yang bisa menimbulkan usia penggunaan jalan akan menjadi lebih pendek daripada perencanaannya. Selain itu, perencanaan yang kurang tepat, kurang ketatnya pengawasan, pelaksanaan yang tidak sesuai dengan rencana yang ada, minim biaya bahkan keterlambatan pengeluaran anggaran dapat menjadi salah satu faktor penyebabnya. Panas, 
suhu udara, air, dan hujan serta mutu awal produk jalan yang jelek juga bisa mempengaruhi. Oleh karena itu, selain perencanaan yang tepat, jalan juga harus dipelihara dengan baik agar dapat melayani pertumbuhan lalu lintas selama umur rencana tersebut.

Pada periode kepengurusan Presiden Joko Widodo, jalan raya merupakan salah satu infrastruktur yang sangat dikembangkan. Jalan raya yang sangat penting untuk menghubungkan suatu tempat dengan tempat lainnya untuk transportasi darat adalah salah satu upaya untuk meningkatkan perekonomian, peningkatan kualitas hidup dan kesejahteraan masyarakat. Perencanaan konstruksi perkerasan dapat dibedakan untuk merencanakan jalan baru dan untuk merawat jalan yang sudah diperkeras. Biasanya perawatan jalan yang sudah diperkeras adalah prasarana jalan yang mengalami kerusakan disebabkan oleh kendaraan dengan variasi sumbu dan roda kendaaan.

Salah satu ruas jalan yang perlu dievaluasi kinerjanya adalah jalan Tol Jakarta-Cikampek. Jalan Tol Jakarta-Cikampek merupakan salah satu jalan bebas hambatan yang menjadi infrastruktur penting nasional dan menjadi urat nadi transportasi penghubung Jakarta dan Bekasi dengan kota - kota lain di Pantai Utara Jawa (Pantura). Tol tersebut mulai dioperasikan oleh PT Jasa Marga Tbk (JSMR) sejak 1988. Jalan Tol yang memiliki total panjang $83 \mathrm{~km}$, saat ini banyak mengalami perubahan konstruksi, sebagian besar ruas Jalan Tol Jakarta-Cikampek saat ini memiliki 4 x 2 lajur, hal ini menandakan padatnya lalu lintas yang melalui jalan tol ini.

Perbaikan jalan nasional mempunyai prosedur yang panjang yakni melalui laporan yang berlanjut usulan ke pemerintah pusat, apabila beruntung maka akan disetujui, tetapi apabila tidak maka akan ditolak dikarenakan belum masuk skala prioritas. Sehingga bila usulan tersebut ditolak maka kebijakan berdasarkan "kearifan lokal" akan diambil untuk perbaikan dengan maksud meminimalisir dampak dari jalan rusak yaitu dengan cara "menambal" dikarenakan keterbatasan anggaran daerah untuk memperbaiki jalan. (Limantara, Winarto, \& Mudjanarko, 2017)

Batasan masalah pada penelitian ini:

1. Analisis kerusakan perkerasan berdasarkan metode IKP.

2. Data kerusakan disurvei dengan menggunakan Google Street View.

3. Alternatif penanganan kerusakan merujuk Permen PU No. 13 Tahun 2011.

4. Data desain lainnya menggunakan asumsi dan data sekunder dengan tetap mengacu pada kondisi di Indonesia.

Berdasarkan masalah yang dirumuskan pada rumusan masalah, maka tujuan dari penelitian ini adalah:

1. Untuk mengetahui kondisi pada jalan Tol Jakarta-Cikampek

2. Menghitung nilai kondisi perkerasan jalan jika dihitung dengan Indeks Kondisi Perkerasan (IKP) pad ruas Tol Jakarta-Cikampek.

3. Untuk mengetahui penanganan seperti apa yang harus dilakukan terhadap kerusakan yang terjadi.

4. Menganalisis prediksi sisa umur ruas Tol Jakarta-Cikampek.

\section{Perkerasan jalan}

Perkerasan jalan adalah campuran antara agregat dan bahan ikat yang digunakan untuk melayani beban lalu lintas. Agregat yang dipakai adalah batu pecah, batu belah ataupun batu kali. Sedangkan bahan ikat yang digunakan adalah aspal, semen ataupun tanah liat. (Yunardhi , 2019)

\section{Perkerasan lentur}

Perkerasan lentur (flexible pavement), yaitu suatu jenis kerusakan yang menggunakan aspal sebagai bahan pengikatnya dan mempunyai sifat lentur dimana setelah pembenahan berlangsung perkerasan akan seperti semula. Pada struktur perkerasan lentur, beban lalu lintas didistribusikan ke tanah dasar secara jenjang dan berlapis (Layer system). Dengan sistem ini beban lalu lintas didistribusikan dari lapisan atas ke lapisan bawahnya. (Putri, Diana, \& Putra, 2016)

\section{Indeks Kondisi Perkerasan}

Indeks Kondisi Perkerasan atau IKP adalah indikator kuantitatif (numerik) kondisi perkerasan yang mempunyai rentang nilai mulai 0 - 100, dengan nilai 0 nya menyatakan kondisi perkerasan paling jelek sementara 100 menyatakan kondisi perkerasan terbaik, seperti yang diilustrasikan pada Gambar 1. (Kusmaryono, I., \& Sepinggan, C. R. D, 2020). 


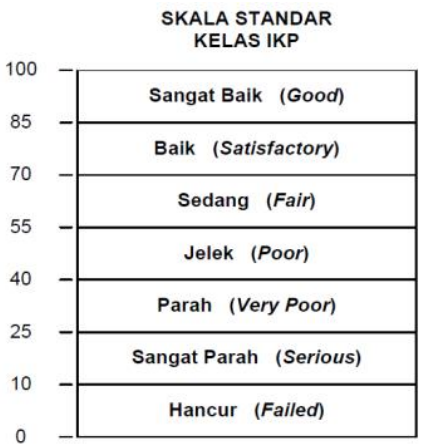

Gambar 1 Hubungan IKP dengan kondisi jalan (Sumber: Pedoman IKP)

IKP menunjukan tingkat kondisi permukaan perkerasan. IKP menunjukan ukuran kondisi perkerasan pada saat melakukan survei. IKP tidak dapat mengukur kapasitas struktural perkerasan atau menunjukan ukuran langsung ketidakrataan. IKP merupakan dasar yang rasional dan obyektif untuk menetukan pemeliharaan dan perbaikan yang diperlukan seperti yang ditujukan pada Tabel 1 untuk jenis-jenis penanganan. (Kementrian Pekerjaan Umum dan Perumahan Rakyat , 2016)

Tabel 1 Jenis penanganan

\begin{tabular}{cc}
\hline IKP & Jenis Penanganan \\
\hline$>85$ & Pemeliharaan rutin \\
$70-85$ & Pemeliharaan berkala \\
$55-70$ & Peningkatan struktural \\
$<55$ & Rekonstruksi \\
\hline
\end{tabular}

(Sumber: PUPR, 2016)

\section{METODE PENELITIAN}

Penelitian ini dimulai dengan mendapatkan data primer berupa pemetaan kerusakan beserta jenis dan dimensi dari tiap kerusakan yang ada. Berikut diagram alir (flowchart) yang tertera pada Gambar 2.

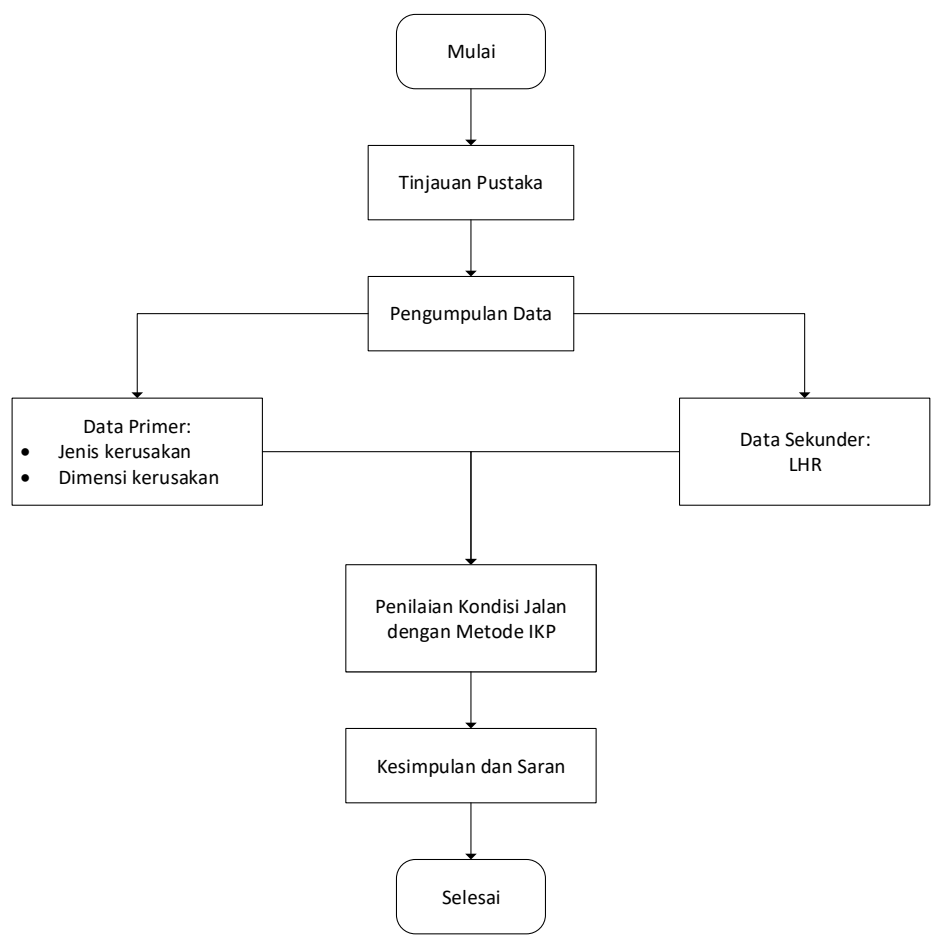

Gambar 2 Diagram alir penelitian 


\section{Prosedur analisis metode Indeks Kondisi Perkerasan}

1. Melakukan survei kondisi perkerasan jalan,

2. Menentukan jenis dan tingkat keparahan kerusakan,

3. Menghitung nilai pengurang,

a. Menentukan luas/panjang/jumlah kerusakannya

b. Menentukan kerapatan dengan menggunakan Persamaan 1

$$
\text { Kerapatan }=\frac{\text { Total }}{\text { Panjang STA } x \text { Lebar STA }} \times 100
$$

Dengan untuk lubang, dihitung jumlah dengan tingkat kerusakan tertentu dalam satu unit sampelnya. Retak tepi, retak refleksi sambungan, penururan bahu, dan retak memanjang/melintang dihitung panjang dengan tingkat kerusakan tertentu dalam satu unit sampel. Dan jenis kerusakan lainnya dihitung luas untuk tiap tingkat tertentu dalam satu unit sampel.

c. Setelah didapat kerapatan, untuk mendapatkan nilai pengurang untuk masing-masing tipe dan tingkat kerusakan menggunakan grafik nilai pengurang (NP) perkerasan beraspal.

4. Menentukan nilai individu yang diijinkan (m)

Jika hanya satu deduct value dengan nilai > 5 untuk lapangan udara dan $>2$ untuk jalan, maka total deduct value digunakan sebagai corrected deduct value, jika tidak maka dilanjutkan ke Persamaan 2.

$$
m=1+\frac{9}{98} x\left(100-N P_{\text {maks }}\right.
$$

dengan $\mathrm{m}=$ nilai individu yang diijinkan; NPmaks = nilai pengurang terbesar

Jika jumlah nilai hasil pengurangan yang lebih kecil dari m ada maka semua nilai pengurang dapat digunakan.

5. Menentukan nilai pengurang terkoreksi

a. Menentukan jumlah nilai pengurang yang lebih besar dari 2 (q).

b. Menentukan nilai total pengurang dengan menjumlahkan tiap nilai pengurang.

c. Menentukan NPT dari perhitungan a) dan b) dengan menggunakan kurva koreksi nilai pengurang, seperti tersaji pada Gambar 3.

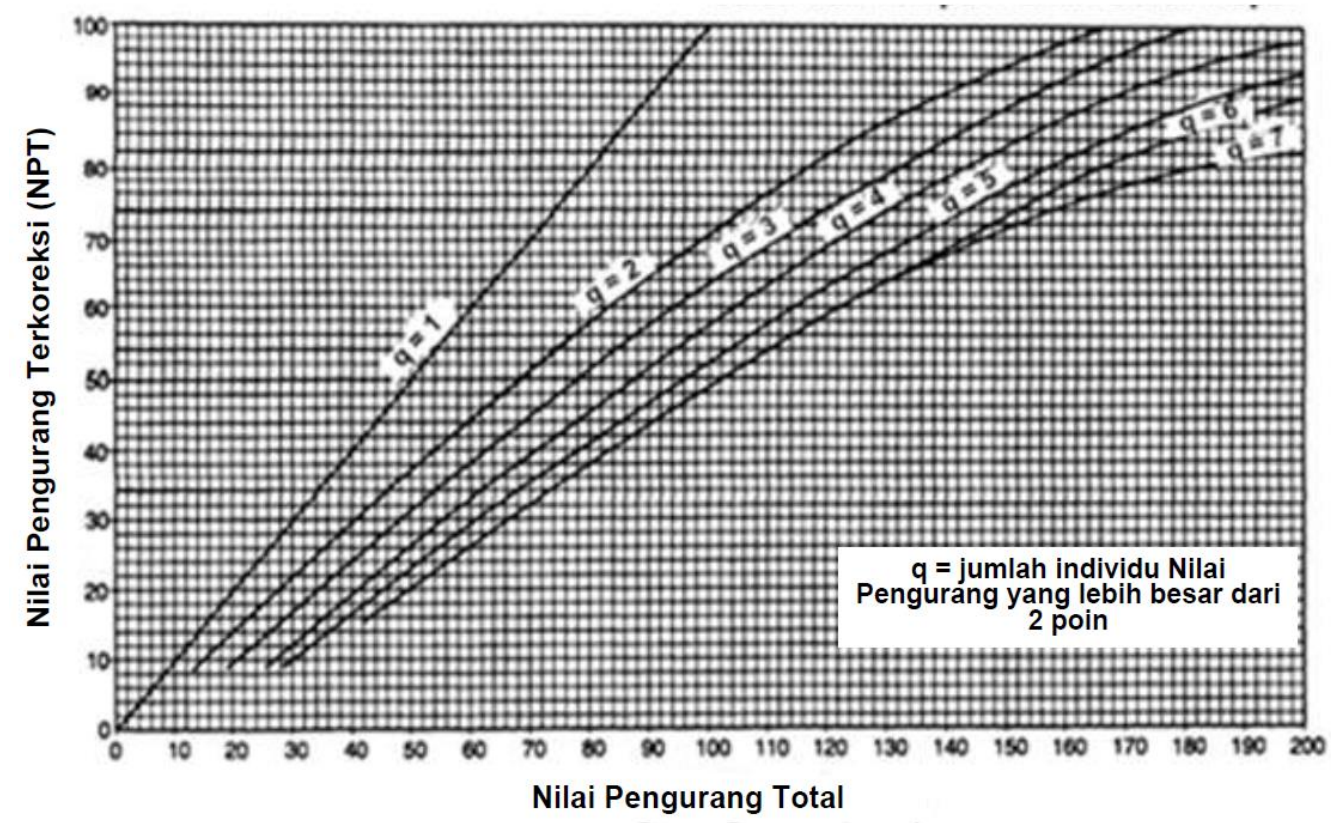

Gambar 3 Kurva untuk menentukan NPT

6. Menghitung nilai IKP (Indeks Kondisi Perkerasan) dengan Persamaan 3.

$$
\text { IKP }=100-N P T m a k s
$$




\section{HASIL DAN PEMBAHASAN}

\section{Indeks Kondisi Perkerasan}

1. Memetakan Kerusakan Jalan

Ruas perkerasan lentur dapat dibagi ke dalam unit sampel dengan panjang $50 \mathrm{~m}$ dan lebar 3,6 m dengan luas unit sampel seluas $180 \mathrm{~m}^{2}$. Sehingga perkerasan dibagi ke dalam 50 unit sampel yang mempunyai panjang $50 \mathrm{~m}$ dan lebar 3,6 m untuk masing - masing lajur. Jadi total unit sampel untuk 4 lajur adalah 200 unit sampel seperti terlihat dalam Gambar 4

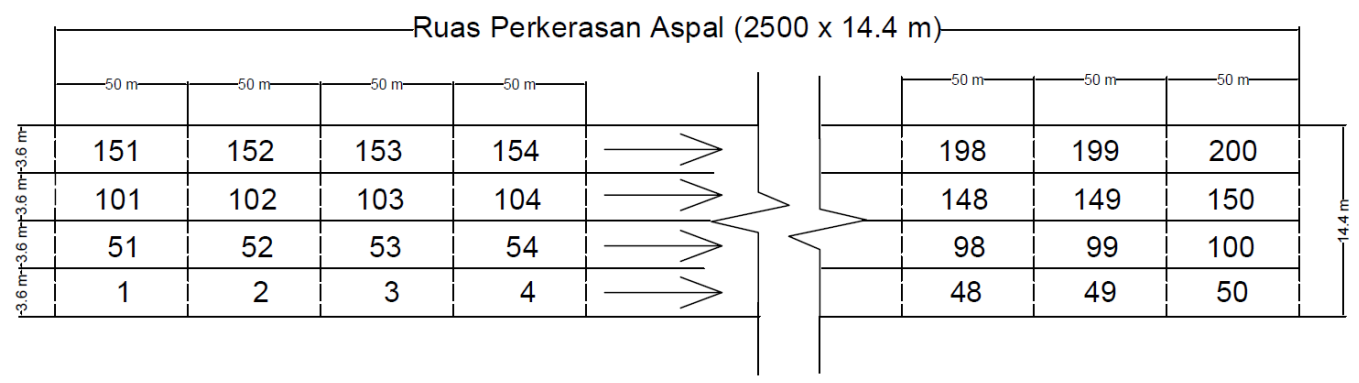

Gambar 4 Pembagian ruas perkerasan aspal menjadi unit sampel

2. Menentukan Jenis Kerusakan Jalan

Adapun dimensi kerusakan jalan dari hasil penelitian yang telah dilakukan penulis pada ruas jalan tol Jakarta Cikampek yang diteliti dengan dimensi yang berbeda-beda dan jenis kerusakan jalan yang berbeda-beda. Berdasarkan hasil penelitian, jenis kerusakan jalan yang terjadi pada ruas Tol Jakarta-Cikampek STA 37+000 s/d 39+500 ditampilkan pada Gambar 5.

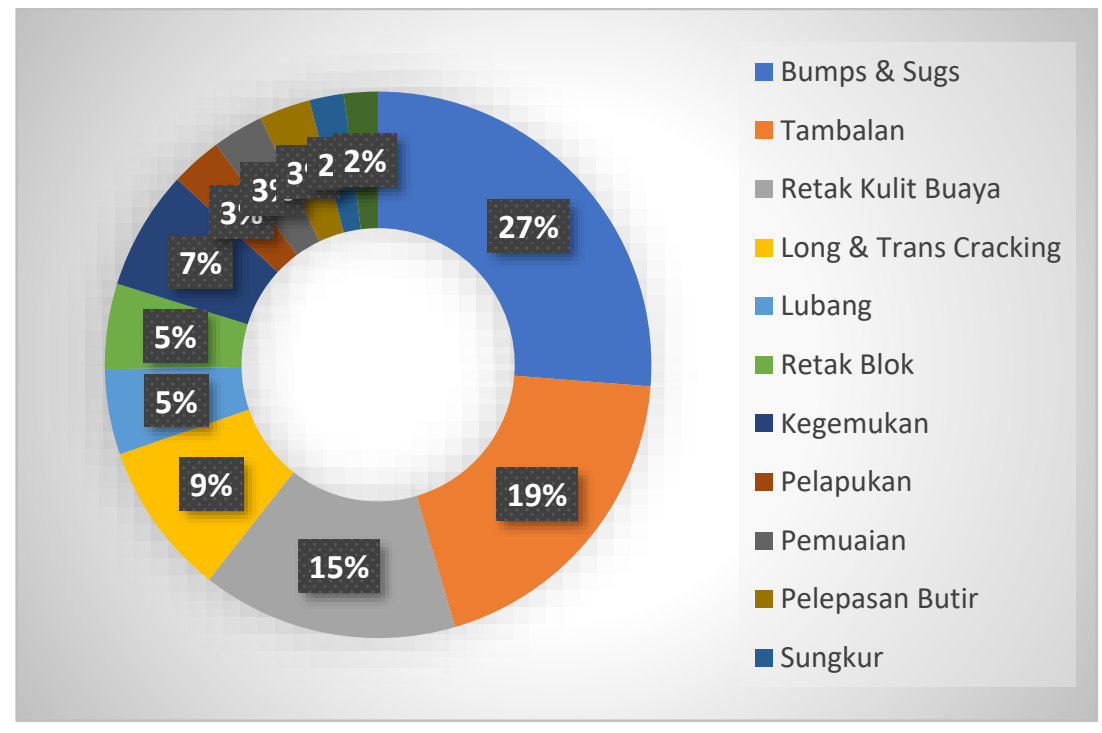

Gambar 5 Jenis kerusakan pada ruas tol Jakarta-Cikampek

Pada Gambar 5, dapat diketahui ruas tol Jakarta - Cikampek memiliki beberapa jenis kerusakan yaitu, retak kulit buaya memiliki 15\% kerusakan, lubang memiliki 5\% kerusakan, jembul dan lekukan memiliki 26\% kerusakan, retak memanjang \& melintang memiliki 9\% kerusakan, tambalan memiliki 19\% kerusakan, kegemukan 7\% kerusakan, retak blok 5\% kerusakan, pemuaian, pelepasan butir dan pelapukan masing-masing 3\% kerusakan, sungkur $2 \%$ dan beberapa kerusakan kecil yaitu alur memiliki $1 \%$ kerusakan dan retak slip $1 \%$. Dari banyaknya kerusakan tersebut masing - masing memiliki tingkat kerusakan yang berbeda-beda.

3. Menghitung Nilai Pengurang (NP)

Tipe-tipe kerusakan yang sudah dicatat dimensinya dihitung. Sebagai contoh, pada stasioning 39+000 - 39+050 arah Jakarta terjadi kerusakan seperti yang ditunjukkan pada Tabel 2. Tabel 3 menunjukkan Nilai Pengurang dari masingmasing jenis dan tingkat kerusakan. 
Tabel 2 Jenis dan luas kerusakan

\begin{tabular}{|c|c|}
\hline Jenis Kerusakan & Perhitungan \\
\hline Retak Kulit Buaya & $4,4 \mathrm{~m} \times 3,5 \mathrm{~m}=15,4 \mathrm{~m}^{2}$ \\
\hline Jembul dan Lekukan & $0,2 \mathrm{~m} \times 0,05 \mathrm{~m}=0,01 \mathrm{~m}^{2}$ \\
\hline Tambalan & $0,6 \mathrm{~m} \times 0,2 \mathrm{~m}=0,12 \mathrm{~m}^{2}$ \\
\hline Pelepasan Butir & $5 \mathrm{~m} \mathrm{x} 0,15 \mathrm{~m}=0,75 \mathrm{~m}^{2}$ \\
\hline
\end{tabular}

Setelah itu yang harus dilakukan adalah menghitung kerapatan.

$$
\begin{array}{cc}
\text { Retak Kulit Buaya }=\frac{15,4}{180} \times 100 \%=8,56 & \text { Pelepasan Butir }=\frac{0,75}{180} \times 100 \%=0,416 \\
\text { Tambalan }=\frac{0,12}{180} \times 100 \%=0,067 & \text { Jembul dan Lekukan }=\frac{0,01}{180} \times 100 \%=0,0056
\end{array}
$$

Tabel 3 Perhitungan nilai pengurang

\begin{tabular}{ccccc}
\hline Jenis Kerusakan & $\begin{array}{c}\text { Tingkat } \\
\text { kerusakan }\end{array}$ & Total & Kerapatan (\%) & Nilai Pengurang \\
\hline Retak Kulit Buaya & $\mathrm{T}$ & 15,4 & 8,56 & 60 \\
Tambalan & $\mathrm{R}$ & 0,01 & 0,067 & 0 \\
Jembul dan Lekukan & $\mathrm{R}$ & 0,75 & 0,416 & 7 \\
Pelepasan Butir & $\mathrm{S}$ & 0,01 & 0,0056 & 0 \\
\hline
\end{tabular}

4. Menghitung Nilai Pengurang Terkoreksi (NPT)

Dalam menghitung nilai pengurang terkoreksi dilakukan dengan cara iterasi sampai q menjadi 1. q adalah jumlah individu NP yang mempunyai nilai lebih dari 2. Hasil perhitungan NPT disajikan pada Tabel 4.

Tabel 4 Perhitungan NPT

\begin{tabular}{cccccc}
\hline No. & \multicolumn{2}{c}{ Nilai Pengurang } & NP Total & Q & NPT \\
\hline 1. & 60 & 7 & 67 & 2 & 49 \\
2. & 60 & 2 & 62 & 1 & 63 \\
\hline
\end{tabular}

5. Menentukan nilai IKP

Berdasarkan perhitungan NPT maksimum diatas, didapat nilai IKP pada stasioning 39+000 - 39+050 arah Jakarta adalah sebagai berikut: $\mathrm{IKP}=100-63=37($ Parah $)$

Dengan langkah tersebut, berdasarkan hasil analisis pada seluruh lokasi peninjauan didapat bahwa $91.5 \%$ ruas Tol Jakarta - Cikampek adalah sangat baik, 5,5\% baik, 1,5\% parah, $1 \%$ sedang, dan 0,5\% jelek, sementara tidak ada ruas jalan yang sangat parah ataupun hancur.

Berdasarkan hasil analisis didapat rata-rata IKP per lajur pada ruas Tol Jakarta-Cikampek STA 37+000 s/d 39+500 adalah:

1. Lajur 1: 95,32 (Sangat Baik)

2. Lajur 2: 93,24 (Sangat Baik)

3. Lajur 3: 98,54 (Sangat Baik)

4. Lajur 4: 98,26 (Sangat Baik)

Maka dapat disimpulkan nilai Indeks Kondisi Perkerasan (IKP) pada ruas Tol Jakarta - Cikampek STA 37+000 39+500 rata-rata adalah 96,32 dengan kelas kondisi sangat baik sesuai Gambar 6 .

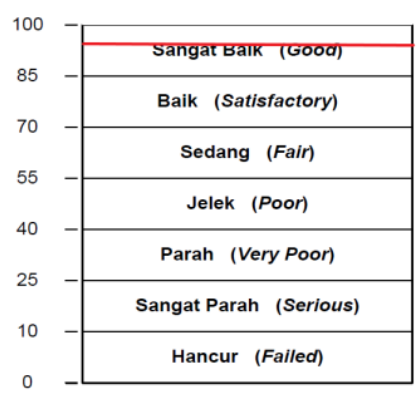

Gambar 6 Kelas kondisi IKP rata-rata 
Kelas kondisi pada jalur yang ditinjau menunjukan bahwa jalur tersebut memenuhi syarat Jalan Nasional Arteri Primer Bebas Hambatan yang harus memiliki kondisi IKP minimal "Baik". Walaupun keseluruhan lajur yang ditinjau mendapatkan nilai yang sangat baik. Namun tetap terdapat beberapa titik yang kondisinya Jelek dan Parah. Hal ini tentu akan mengganggu kelancaran mobilitas dan dapat berdampak ke keselamatan. Sehingga pengelola Jalan Tol Jakarta-Cikampek perlu memastikan bahwa setiap titik memiliki kondisi jalan yang baik.

\section{KESIMPULAN DAN SARAN}

\section{Kesimpulan}

Berdasarkan hasil analisis yang dilakukan dapat disimpulkan sebagai berikut:

1. Metode IKP menghasilkan nilai IKP 85-100 atau sangat baik berjumlah 183 unit sampel, $70-85$ atau baik memiliki 11 unit sampel, 55-70 atau sedang memiliki 2 unit sampel, 40-55 atau jelek memiliki 1 unit sampel, 25-40 atau parah memiliki 3 unit sampel, sedangkan 10-25 atau sangat parah dan 0-10 atau hancur tidak terdapat satu pun unit sampel.

2. Berdasarkan hasil perhitungan IKP, didapat nilai IKP rata-rata 96,32 atau termasuk sangat baik. Metode IKP memiliki tingkat jenis penanganan tiap nilai IKP. Menurut pedoman IKP, jenis penanganan yang harus dilakukan dengan nilai IKP rata-rata 96,32 adalah pemeliharaan rutin.

3. Berdasarkan hasil analisis yang dilakukan terdapat 2 unit sampel yang memiliki kondisi sedang, 3 unit sampel memiliki kondisi parah dan 1 unit kondisi jelek, yang membutuhkan untuk penanganan khusus seperti peningkatan struktural atau rekonstruksi.

\section{Saran}

Hal-hal yang perlu dilakukan untuk penelitian selanjutnya adalah:

1. Untuk penelitian selanjutnya, perlu untuk survei secara langsung, supaya hasil yang didapat lebih maksimal.

2. Perlu diteliti dengan metode yang beragam untuk dapat membandingkan tingkat keakuratan sebuah metode.

\section{DAFTAR PUSTAKA}

Limantara, A. D., Winarto, S. W., \& Mudjanarko, S. W. (2017). Sistem Pakar Pemilihan Model Perbaikan Perkerasan Lentur berdasarkan Indeks Kondisi Perkerasan (Pci). Prosiding Semnastek, TS-003

Kementerian Pekerjaan Umum dan Perumahan Rakyat. (2016). Pedoman Penentuan Indeks Kondisi Perkerasan (IKP). Jakarta: Kementerian Pekerjaan Umum dan Perumahan Rakyat

Kusmaryono, I., \& Sepinggan, C. R. D. (2020). Analisi Kondisi Kerusakan Permukaan Perkerasan Jalan Lentur Menggunakan Pedoman Penentuan Indeks Kondisi Perkerasan Dan Penanganannya Pada Jalan Raya Bogor di Kota Depok. Jurnal Teknik Sipil, X(1), 25-33

Putri, V. A., Diana, I. W., \& Putra, S. (2016). Identifikasi Jenis Kerusakan Pada Perkerasan Lentur (Studi Kasus Jalan Soekarno-Hatta Bandar Lampung). Jurnal Rekayasa Sipil dan Desain, 4(2), 197-204.

Yunardhi, H. (2019). Analisa Kerusakan Jalan Dengan Metode PCI dan Alternatif Penyelesaiannya (Studi Kasus: Ruas Jalan di Panjaitan). Teknologi Sipil, 2(2). 
